\section{Halocuprate(I) Synthesis with in situ Alkylated DABCO}

\author{
Sebastian Maderlehner ${ }^{[a]}$ and Arno Pfitzner*[a]
}

Keywords: DABCO, Halocuprate(I), Luminescence

Two halocuprates(I) $\left[\mathrm{H}_{3} \mathrm{CN}\left(\mu-\mathrm{C}_{2} \mathrm{H}_{4}\right)_{3} \mathrm{NCH}_{3}\right]{ }_{\infty}^{1}\left[\mathrm{Cu}_{2} X_{4}\right](X=$ $\mathrm{Br}, \mathrm{I})$ were synthesized in a hydrothermal reaction in an acetonitrile/methanol mixture and characterized by single crystal $\mathrm{X}$-ray diffraction. Both compounds crystallize monoclinic with $a=9.161(2) \AA, b=10.930(2) \AA, c=15.342(3) \AA, \beta=$ $93.79(3)^{\circ} V=1532.9(5) \AA^{3}, Z=4$, space group $P 2_{1} / n$ (No. 14) $(X=\mathrm{Br})$ and $a=15.8506(2) \AA, b=9.4356(1) \AA, c=$ 22.9636(3) $\AA, \beta=89.989(1)^{\circ} V=3434.43(7) \AA^{3}, Z=8$ and space group $P 2_{1}$ (No. 4) $(X=\mathrm{I})$, respectively. They contain polymeric halocuprate(I) anions and 1,4-dimethyl-1,4-diazoniabicyclo[2.2.2]-octane $\left(\mathrm{DABCOMe}_{2}{ }^{2+}\right.$ ) cations generated in situ. The complex anions consist of chains of trans edge-sharing $\mathrm{CuX}_{4}$ tetrahedra which are strongly kinked at every $2^{\text {nd }}$ junction. The cations are embedded between the chains on the flat sides of the kinked junctions, see Figure 1.

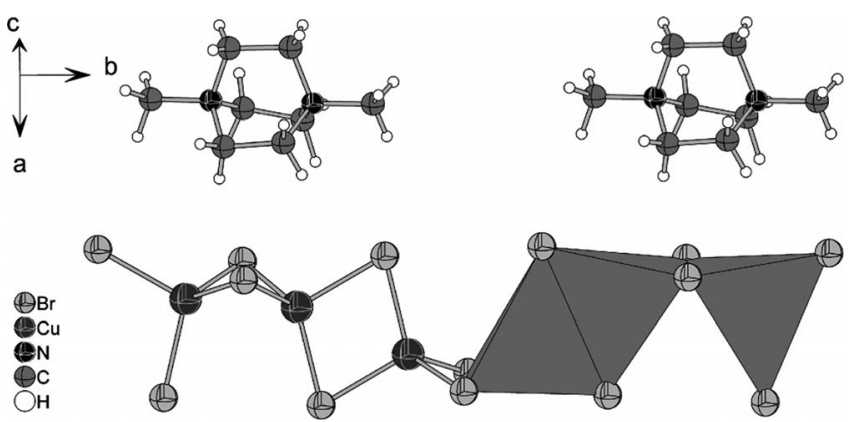

Figure 1. Section of the complex anion with surrounding cations

The chains are hexagonally packed. The cation is formed by $\mathrm{DABCOH}_{2}{ }^{2+}$ and methanol in an $S_{N} 2$ reaction. Both compounds show a green luminescence at room temperature which undergoes a slight blue-shift upon cooling to liquid nitrogen temperature.

\section{One-Pot Fabrication of Hollow Nano-Particulate Metal Oxides by Use of Sugars as Sacrificial Templates}

\section{Haitham Abdelaal ${ }^{[a]}$ and Bernd Harbrecht*[a]}

Keywords: One-pot fabrication; Hollow oxides

Using monosaccharide as sacrificial template in one-pot hydrothermal method is efficient to fabricate nano-sized oxides with hollow structure. nanoparticulate $\alpha-\mathrm{Fe} 2 \mathrm{O} 3, \mathrm{Co} 3 \mathrm{O} 4, \mathrm{Cr} 2 \mathrm{O} 3$ and $\mathrm{ZnO}$ with hollow structures have been produced via this route. Due to the low density, large surface area and hollow nature, the hollow oxides nanoparticles (HONPs) have potential applications in various fields such as, selective separation, catalysis, gas adsorbents, and heavy metal ions adsorbents. ${ }^{[1,2]}$ The fabrication process of the hollow oxides using both glucose and fructose was performed. These sacrificial cores inherit functional groups that facilitate the precipitation of metal precursors on their reactive surfaces. Applying fructose as a template enables reduction of the reaction temperature and time if compared with reaction with glucose. The particles sizes, however, are smaller if glucose is used as template.

Correlations between the particle size and the Concentration of the monosaccharide as well as the ratio of the amount of substance of metal precursor and monosaccharide are uncovered. Moreover, important factors critical to fine-tune the final particle size and shape are temperature, reaction time and the addition of acetic acid apparently acting as a catalyst. A mechanism of the formation of HNOPs by this route is proposed.

[1] J. Yuan, X. Zhang, H. Qian, J. Mag. Mag. Mater. 2010, 322, $2172-$ 2176.

[2] X. Sun, J.Liu, Y.Li, Chem.Eur. J. 2006, 12, 2039-2047.

\footnotetext{
* Prof. Dr. A. Pfitzner

E-Mail: arno.pfitzner@chemie.uni-r.de

[a] Institut für anorganische Chemie, Universität Regensburg, Universitätsstraße 31,93040 Regensburg, Germany
}

* Prof. Dr. B. Harbrecht

E-Mail: haitham.abdelaal@ chemie.uni-marburg.de

[a] Fachbereich Chemie und Wissenschaftliches Zentrum für Materialwissenschaften, Philipps-Universität, 35032 Marburg, Germany 